\title{
DG FED MULTILEVEL INVERTER BASED D-STATCOM FOR VARIOUS LOADING CONDITIONS
}

\author{
Naarisetti Srinivasa Rao ${ }^{1}$ and R. Kalyani ${ }^{2}$ \\ ${ }^{1}$ Associate Professor, Department of Electrical \& Computer Engineering \\ College of Engineering and Technology, Dilla University, Dilla, Ethiopia \\ ${ }^{2}$ Assistant Professor, Department of Electrical \& Electronics Engineering, Mahaveer \\ Institute of Engineering and Technology, Bandlaguda, Telangana, India.
}

\begin{abstract}
During the past few decades, power industries have proved that the adverse impacts on the $P Q$ can be mitigated or avoided by conventional means, and that technique using fast controlled force commutated power electronics $(P E)$ are even more effective. $P Q$ compensators can be categorized into two main types. One is shunt connected compensation device that effectively eliminates harmonics. The other is the series connected device, which has an edge over the shunt type for correcting the distorted system side voltages and voltage sags caused by power transmission system faults. The STATCOM used in distribution systems is called DSTACOM (Distribution-STACOM) and its configuration is the same, but with small modifications. Recent advances in the power-handling capabilities of static switch devices such as $3.3 \mathrm{kV}$, $4.5 \mathrm{kV}$, and $6.5 \mathrm{kV}$ Insulated Gate Bipolar Transistors (IGBTs) with voltage rating commercially available, have made the use of the voltage source inverters (VSI) feasible for high-power applications. High power and high-voltage conversion systems have become very important issues for the power electronic industry handling the large ac drive and electrical power applications at both the transmission and distribution levels. For these reasons, new families of multilevel inverters have emerged as the solution for working with higher voltage levels. Multilevel inverters (MLI) include an array of power semiconductors and capacitor voltage sources, the output of which generate voltages with stepped waveforms. These converter topologies can generate high-quality voltage waveforms with power semiconductor switches operating at a frequency near the fundamental. It significantly reduces the harmonics problem with reduced voltage stress across the switch. This research work is mainly focusing on application of multilevel DSTATCOM for power quality improvement in distribution system with integration of RES. Matlab/Simulink based model is developed and simulation results are presented.
\end{abstract}

\section{KEYWORDS}

DSTATCOM, Cascaded H-Bridge Multilevel Inverter, Pulse Width Modulation, renewable energy sources

\section{INTRODUCTION}

"A power electronic based system and other static equipment that provide control of one or more AC transmission system parameters to enhance controllability and increase power transfer capability [3]." Among FACTS controllers, the shunt controllers have shown feasibility in term of cost effectiveness in a wide range of problem-solving from transmission to distribution levels [1, 2]. For decades, it has been recognized that the transmittable power through transmission/distribution lines could be increased, and the voltage profile along the transmission/distribution line could be controlled by an appropriate amount of compensated reactive current or power. Moreover, the shunt controller can improve transient stability and can 
damp out power oscillation. Using a high-speed power converter, the shunt controller can further alleviate or even cancel the flicker problem caused by electrical arc furnaces and regulate the voltage levels within certain criteria [7].

In principle, all shunt-type controllers inject additional current into the system at the point of common coupling (PCC). An impedance of the shunt controller, which is connected to the line voltage, causes a variable current flow, and hence represents an injection of current into the line. As long as the injected current is in phase quadrature with the line voltage, the shunt controller only supplies or consumes variable reactive power. Among recently developed power converter topologies, multilevel converters have become an important technology, and have been utilized in high-power applications, particularly FACTS controllers [5, 6]. Several multilevel converter topologies have been developed to demonstrate their superiority in such applications. With converter modules in series, and with balanced voltage-sharing among them, lower-voltage switches can possibly be used in high-voltage systems. Thus, the low-voltage-oriented insulated gate bipolar transistor (IGBT) devices can be stacked for medium-voltage systems [3, 4]. For higher-voltage applications, however, efforts have been made to use GTO-based devices for multilevel converters.

In harmonic elimination, reactive power compensation, cascaded-multilevel VSCs with separated DC capacitors are somewhat the most feasible topology for many reasons. The cascadedmultilevel converter (CMC) is constructed with a number of identical H-bridge converters. This modular feature makes the cascaded converter very attractive and simple in structure. The cascaded converter topology not only simplifies hardware manufacturability, but also makes the entire system flexible in terms of power capability. In addition, for the same power capability, the cascaded converter requires fewer total components. Auxiliary components, such as the clamped diodes and capacitors, are not required in the CMC topology [7, 8]. The CMC-based DSTATCOM, however, challenges researchers to improve its dynamic responses and to balance its excessive number of DC capacitor voltages. To date, several papers have discussed the configurations and control strategies for the reactive power compensation systems that utilize CMCs based on these previous works, an accurate model and an effective control technique associated with the simple DC capacitor balancing strategy are elements important to achieving a high-performance, stable, cost-effective CMC-based D-STATCOM [6, 8]. Finally the proposed DSTATCOM is used for integrating the PV system.

\section{Cascaded Multilevel baSed Voltage-Source Converters for D-STATCOM APPLICATION}

An attractive to the seven-level converter is a multilevel VSC. Without semiconductor devices connected in series, the multilevel converters show feasible capability of clamping the voltages across individual devices below their limitations. This allows the recent semiconductor devices to be utilized in higher-voltage applications without incurring voltage sharing problems. Another significant advantage of the multilevel configuration is the harmonic reduction in the output waveform with very low switching frequency, line frequency for example. Besides the highvoltage capability, multilevel converters also provide other advantages over the seven-level converters. The multilevel converter in the four following aspects: output voltage quality, DC capacitance requirement, losses and power capacity. The schematics of the cascaded multilevelconverter are shown in Fig.1. Respectively.

With its modularity and flexibility, the CMC shows superiority in high-power applications, especially shunt and series connected FACTS controllers. The CMC synthesizes its output near sinusoidal voltage waveforms by combining many isolated voltage levels. With a sufficiently high number of voltage levels, a premium-quality output waveform with fast system response can 
be achieved by switching the main power semiconductor devices only at the line frequency. This naturally minimizes the entire system losses and the output filter requirement. In addition, by adding more H-bridge converters, the amount of Var can simply increased without redesign

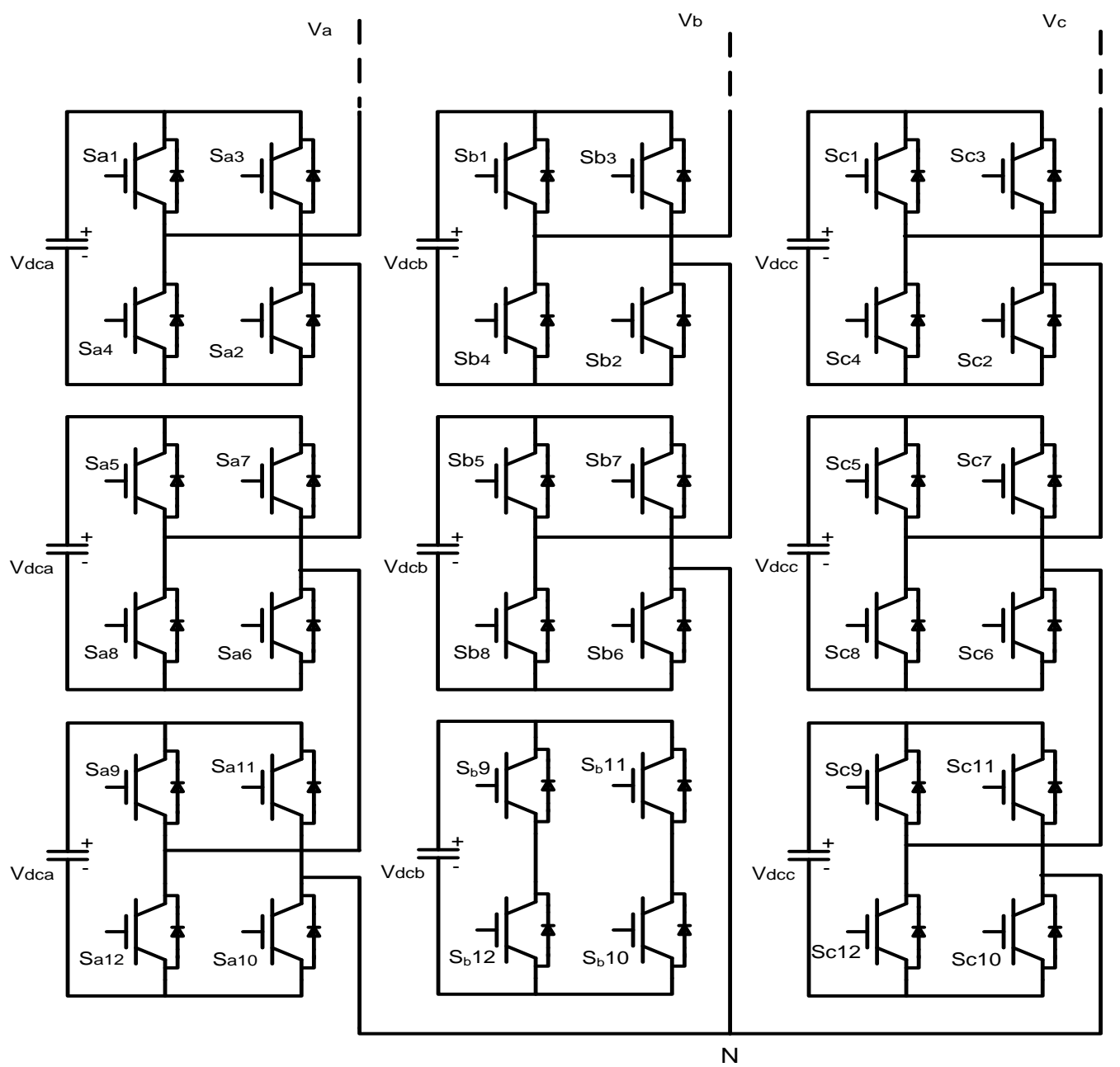

Fig.1. Schematic Diagram of 7-Level Cascaded Multilevel Converter

the power stage, and build-in redundancy against individual $\mathrm{H}$-bridge converter failure can be realized. Moreover, a three-phase CMC topology is essentially composed of three identical phase legs of the series-chain of H-bridge converters, which can possibly generate different output voltage waveforms and offers the potential for AC system phase-balancing. This feature is impossible in other VSC topologies utilizing a common DC link. By nature of this topology, however, the CMC is impossible to apply in intertie or back-to back applications, such as universal power flow controllers (UPFC). Fortunately, with energy storage systems, the CMC can now successfully overcome this limitation. This combination also enhances recent low-voltage energy-storage system technology for high-voltage applications. A great combination of the DSTATCOM concept and the CMC topology is a promising controller in the modern FACTS technology.

\section{Control Strategy}

IRP theory was initially proposed by Akagi. This theory is based on the transformation of three phase quantities to two phase quantities in $\alpha-\beta$ frame and the calculation of instantaneous active 
and reactive power in this frame. A basic block diagram of this theory is shown in fig.2. Sensed inputs $V s a, V s b, V s c$ and $i L a, i L b, i L c$ are fed to the controller, and these quantities are processed to generate reference current commands $\left(i_{S a}^{*}, i_{S b}^{*}, i_{S c}^{*}\right)$, which are fed to a pulse width modulation (PWM) signal generator to generate final switching signals fed to the D-STATCOM; therefore this block works as controller for D-STATCOM.

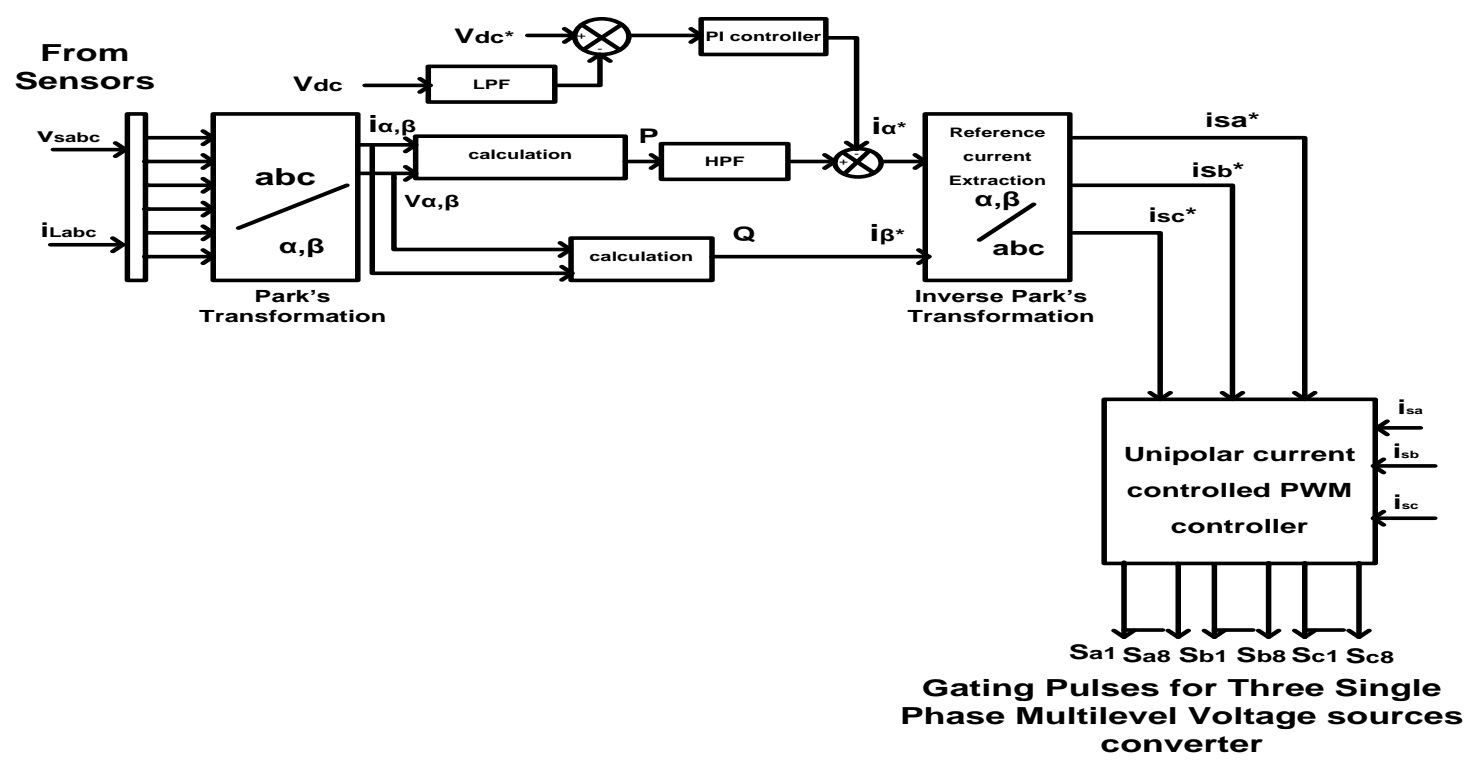

Fig.2. Block Diagram of Proposed Control Strategy- Instantaneous Real \& Reactive Power Theory

The system terminal voltages are given as

$$
\begin{aligned}
& v a=V m \sin (\omega t) \\
& v b=V m \sin (\omega t-2 \pi / 3) \\
& v c=V m \sin (\omega t-4 \pi / 3)
\end{aligned}
$$

And the respective load currents are given as

$$
\begin{aligned}
i_{L a} & =\sum I_{L a n} \sin \left\{n(\omega t)-\theta_{a n}\right\} \\
i_{L b} & =\sum I_{L b n} \sin \left\{n(\omega t-2 \pi / 3)-\theta_{b n}\right\} \\
i_{L c} & =\sum I_{L c n} \sin \left\{n(\omega t-2 \pi / 3)-\theta_{c n}\right\}
\end{aligned}
$$

In a-b-c coordinates, $a, b$, and $c$ axes are fixed on the same plane, apart from each other by $2 \pi / 3$. The instantaneous space vectors va and iLa are set on the "a" axis, and their amplitude varies in positive and negative directions with time. This is true for the other two phases also. These phasors can be transformed into $\alpha-\beta$ coordinates using Park's transformation as follows:

$$
\begin{aligned}
& {\left[\begin{array}{l}
v_{\alpha} \\
v_{\beta}
\end{array}\right]=\sqrt{\frac{2}{3}}\left[\begin{array}{ccc}
1 & -1 / 2 & -1 / 2 \\
0 & \sqrt{3} / 2 & -\sqrt{3} / 2
\end{array}\right]\left[\begin{array}{l}
v_{\alpha} \\
v_{b} \\
v_{c}
\end{array}\right]} \\
& {\left[\begin{array}{l}
i_{\alpha} \\
i_{\beta}
\end{array}\right]=\sqrt{\frac{2}{3}}\left[\begin{array}{ccc}
1 & -1 / 2 & -1 / 2 \\
0 & \sqrt{3} / 2 & -\sqrt{3} / 2
\end{array}\right]\left[\begin{array}{l}
i_{a} \\
i_{b} \\
i_{c}
\end{array}\right]}
\end{aligned}
$$


Where $\alpha$ and $\beta$ axes are the orthogonal coordinates. Conventional instantaneous power for threephase circuit can be defined as

$$
p=v_{\alpha} i_{\alpha}+v_{\beta} v_{\beta}
$$

Where $\mathrm{p}$ is equal to conventional equation

$$
p=v_{a} i_{a}+v_{b} i_{b}+v_{c} i_{c}
$$

Similarly, the IRP is defined as

$$
q=-v_{\beta} i_{\alpha}+v_{\alpha} i_{\beta}
$$

Therefore, in matrix form, instantaneous real and reactive power are given as

$$
\left[\begin{array}{l}
p \\
q
\end{array}\right]=\left[\begin{array}{cc}
v_{\alpha} & v_{\beta} \\
-v_{\beta} & v_{\alpha}
\end{array}\right]\left[\begin{array}{l}
i_{\alpha} \\
i_{\beta}
\end{array}\right]
$$

The $\alpha-\beta$ currents can be obtained as

$$
\left[\begin{array}{l}
i_{\alpha} \\
i_{\beta}
\end{array}\right]=\frac{1}{\Delta}\left[\begin{array}{cc}
v_{\alpha} & v_{\beta} \\
-v_{\beta} & v_{\alpha}
\end{array}\right]\left[\begin{array}{l}
p \\
q
\end{array}\right]
$$

Where

$$
\Delta=v_{\alpha}^{2}+v_{\beta}^{2}
$$

Instantaneous active and reactive powers $p$ and $q$ can be decomposed into an average (dc) and an oscillatory component.

$$
\begin{aligned}
& p=\bar{p}+\tilde{p} \\
& q=\bar{q}+\tilde{q}
\end{aligned}
$$

Where $\bar{p}$ and $\bar{q}$ are the average (dc) part and $\tilde{p}$ and $\tilde{q}$ are the oscillatory (ac) part of these real and reactive instantaneous powers. Reference source currents are calculated to compensate the IRP and the oscillatory component of the instantaneous active power. Therefore, the reference source currents $i_{s \alpha}^{*}$ and $i_{s \beta}^{*}$ in $\alpha-\beta$ coordinate are expressed as

$$
\left[\begin{array}{l}
i_{s \alpha}^{*} \\
i_{s \beta}^{*}
\end{array}\right]=\frac{1}{\Delta}\left[\begin{array}{cc}
v_{\alpha} & -v_{\beta} \\
v_{\beta} & v_{\alpha}
\end{array}\right]\left[\begin{array}{c}
\bar{p} \\
0
\end{array}\right]
$$

Theses currents can be transformed in a-b-c quantities to find the reference currents in a-b-c coordinates using inverse transformation.

$$
\left[\begin{array}{l}
i_{s a}^{*} \\
i_{s b}^{*} \\
i_{s c}^{*}
\end{array}\right]=\sqrt{\frac{2}{3}}\left[\begin{array}{ccc}
1 / \sqrt{2} & 1 & 0 \\
1 / \sqrt{2} & -1 / 2 & \sqrt{3} / 2 \\
1 / \sqrt{2} & -1 / 2 & -\sqrt{3} / 2
\end{array}\right]\left[\begin{array}{c}
i_{0}^{*} \\
i_{s \alpha}^{*} \\
i_{s \beta}^{*}
\end{array}\right]
$$

Where $i_{0}^{*}$ is the zero sequence components, which is zero in three- phase three wire system.

\section{Photovoltaic System}


In the crystalline silicon PV module, the complex physics of the PV cell can be represented by the equivalent electrical circuit shown in Fig. 4. For that equivalent circuit, a set of equations have been derived, based on standard theory, which allows the operation of a single solar cell to be simulated using data from manufacturers or field experiments.

The series resistance RS represents the internal losses due to the current flow. Shunt resistance Rsh, in parallel with diode, this corresponds to the leakage current to the ground. The single exponential equation which models a PV cell is extracted from the physics of the PN junction and is widely agreed as echoing the behavior of the PV cell

$$
I=I_{L}-I_{S C}\left(\exp \frac{\left(V+R_{S} I\right)}{V_{L}}-1\right)-\frac{\left(V+R_{S} I\right)}{R_{S h}}
$$

The number of PV modules connected in parallel and series in PV array are used in expression. The Vt is also defined in terms of the ideality factor of PN junction (n), Boltzmann's constant $(\mathrm{KB})$, temperature of photovoltaic array (T), and the electron charge (q). Applied a dynamical electrical array reconfiguration (EAR) strategy on the photovoltaic (PV) generator of a gridconnected PV system based on a plant-oriented configuration, in order to improve its energy production when the operating conditions of the solar panels are different. The EAR strategy is carried out by inserting a controllable switching matrix between the PV generator and the central inverter, which allows the electrical reconnection of the available PV modules. 
International Journal on Cybernetics \& Informatics (IJCI) Vol. 5, No. 1, February 2016

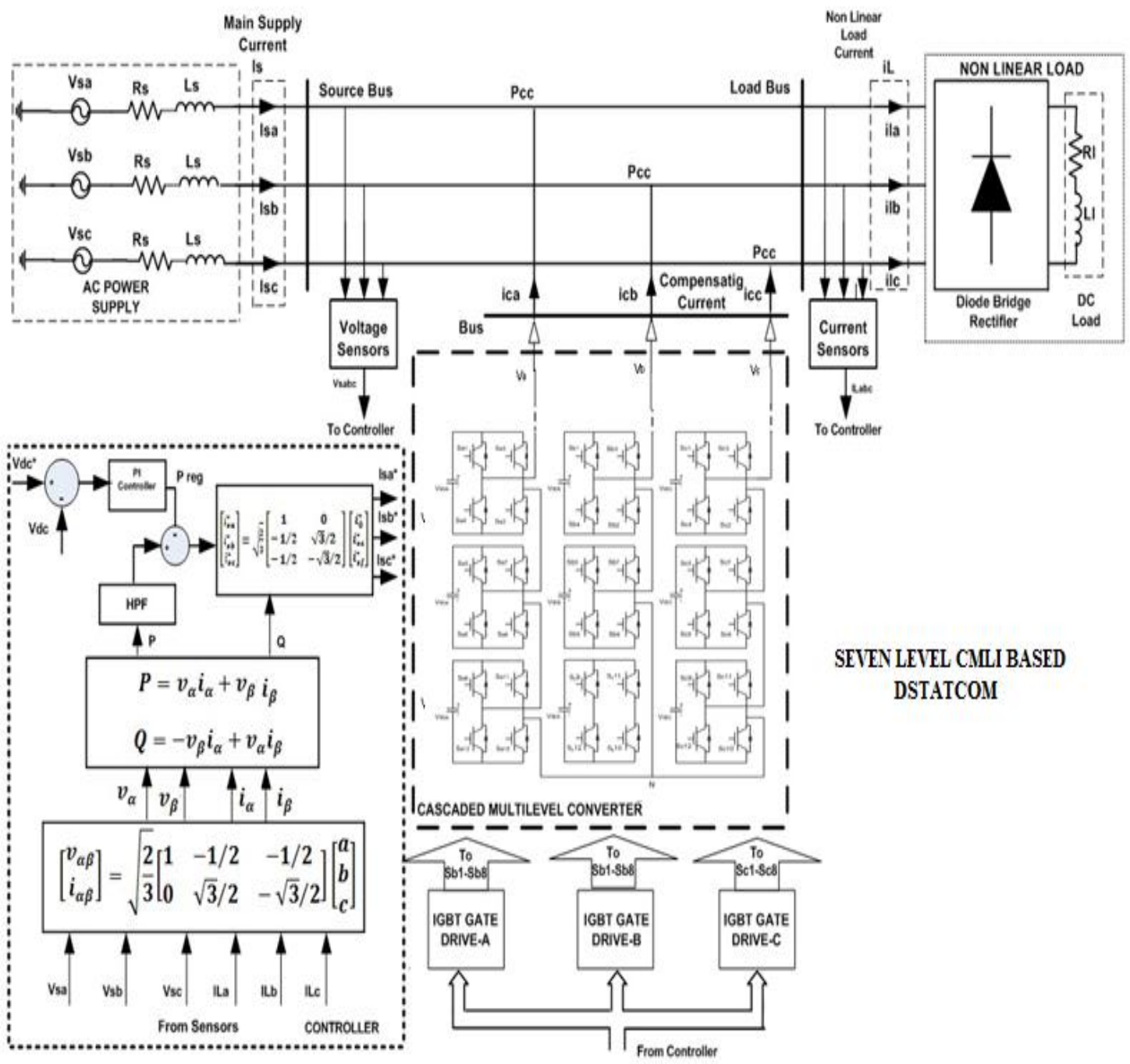

Fig.3.Schematic diagram of non-linear load with cascaded seven level inverter D-STATCOM

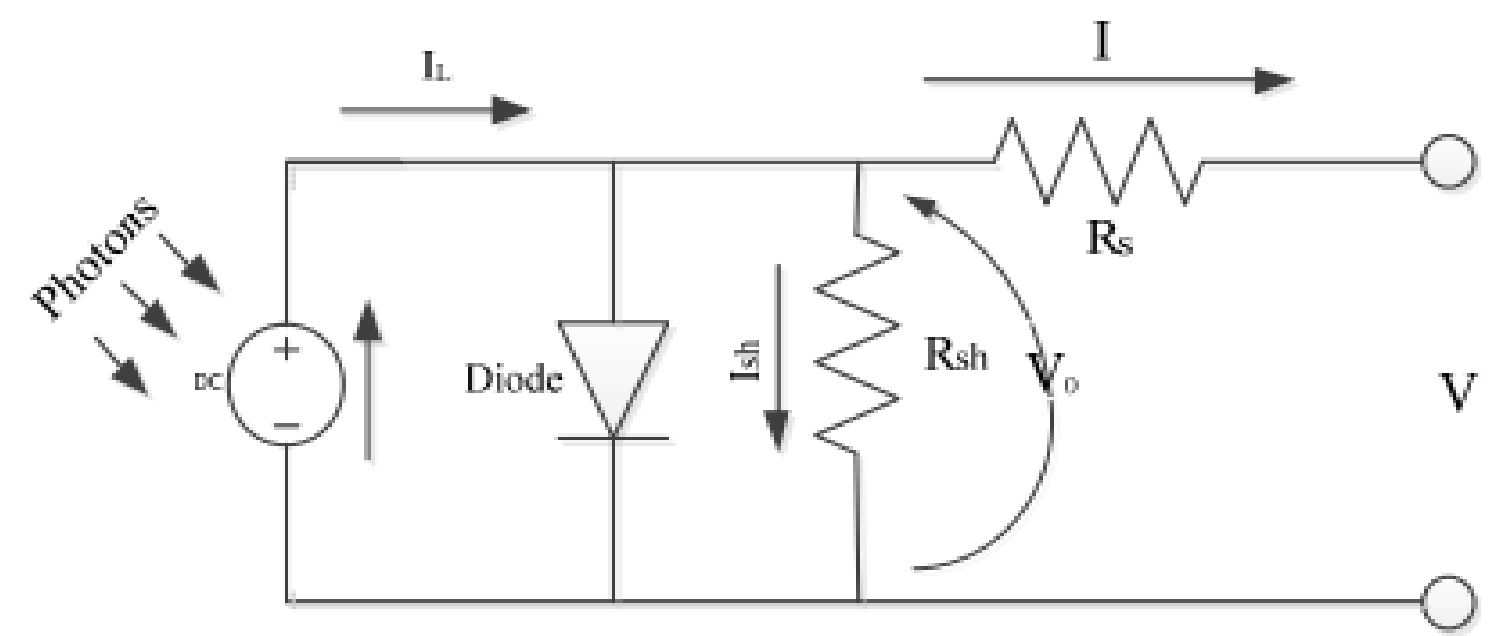

Fig.4 Equivalent electrical circuit of a PV module

\section{DG INTEGRATION WITH DSTATCOM}


Distributed generation (or DG) generally refers to small scale electric power generators that produce electricity at a site close to customers or that are tied to an electric distribution system. Distributed generators include, but are not limited to synchronous generators, induction generators, reciprocating engines, micro turbines (combustion turbines that run on high energy fossil fuels such as oil, propane, natural gas, gasoline or diesel), combustion gas turbines, fuel cells, solar photovoltaic's, and wind turbines. Globally, the long-term technical potential of wind energy is believed to be five times total current global energy production, or 40 times current electricity demand. This could require wind turbines to be installed over large areas, particularly in areas of higher wind resources. Offshore resources experience average wind speeds of $\sim 90 \%$ greater than that of land, so offshore resources could contribute substantially more energy.

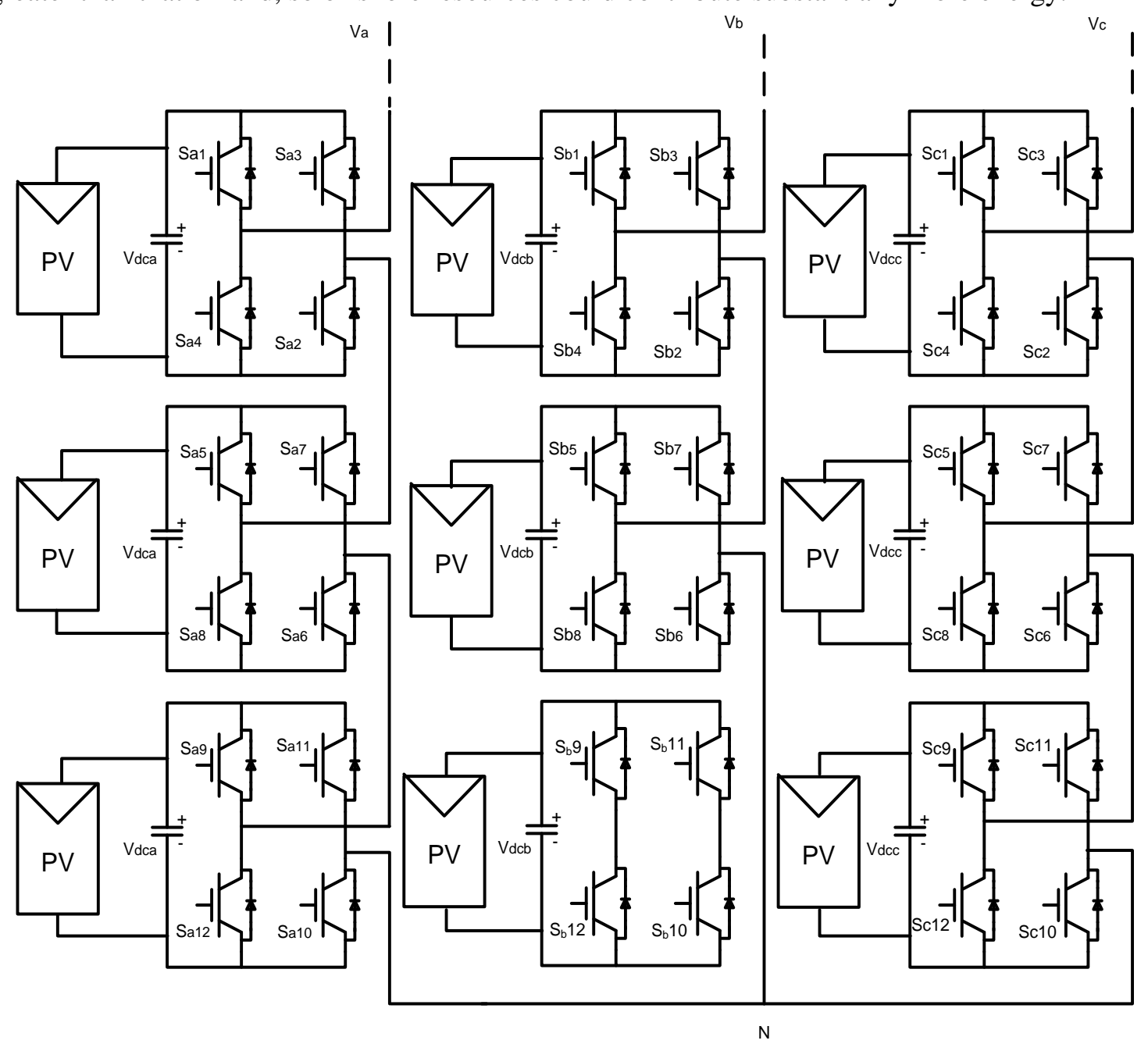

Fig.5.schematic diagram of DG integration with seven level inverter

\section{Matlab/Simulation Results}

Here the simulation is carried out by two cases

Case.1. Balanced Non-linear load with seven level cascaded multilevel D-STATCOM.

Case.2. Un-balanced Non-linear load with seven level Cascaded multilevel D-STATCOM.

Case1. Balanced Non-linear load with seven level cascaded multilevel D-STATCOM. 
International Journal on Cybernetics \& Informatics (IJCI) Vol. 5, No. 1, February 2016

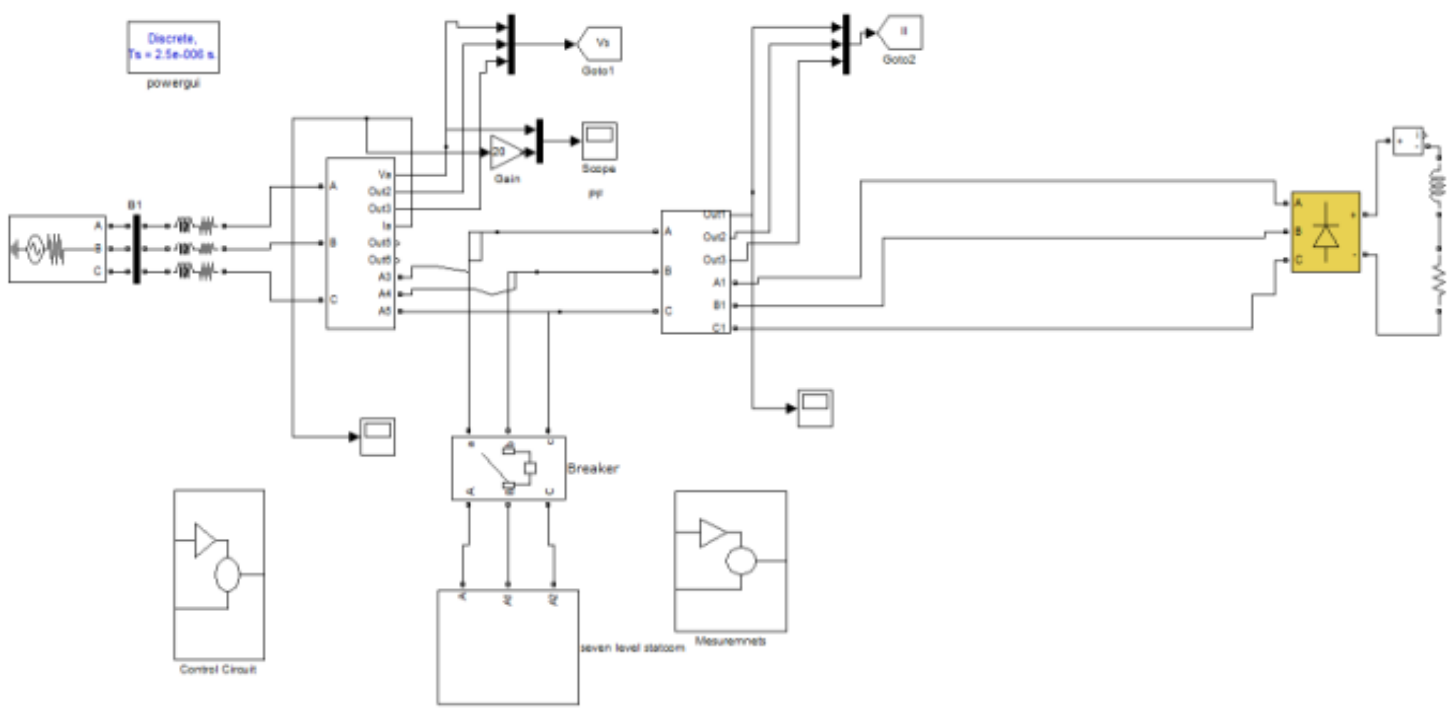

Fig.6.Matlab/Simulink model of balanced non-linear load with seven level cascaded multilevel DSTATCOM

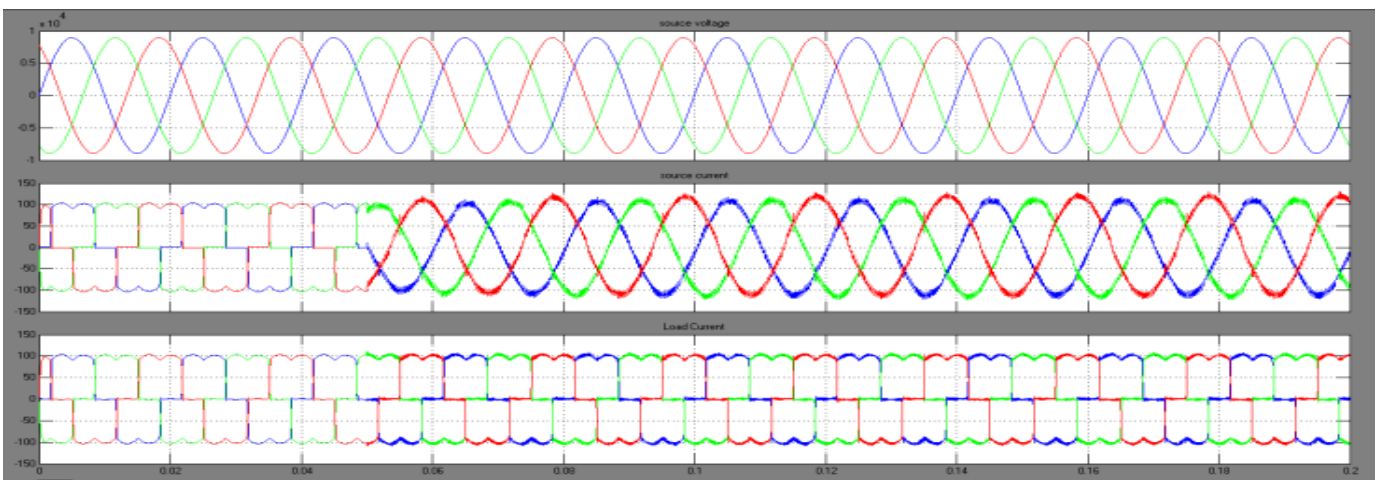

Figure 7: Source voltage, Source current, Load current

Figure 7 shows the source voltages, source currents and load currents respectively with balanced non-linear load and Cascaded Multilevel Seven level.

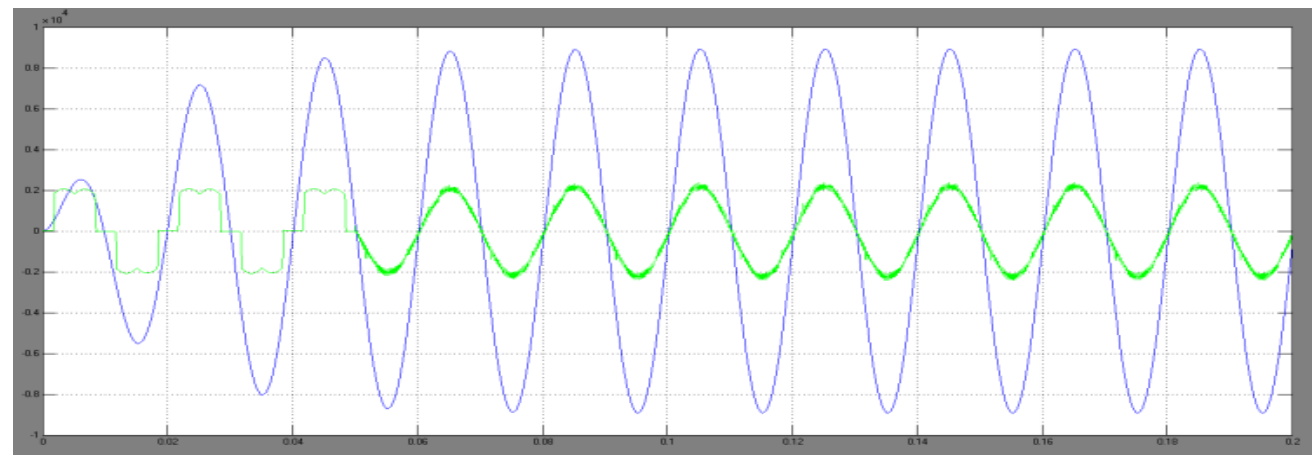

Figure 8: Power Factor with balanced non-linear load

Figure 8 shows the power factor waveforms of the designed system with balanced non-liner load seven level cascaded multilevel D-STATCOM .The waveform clearly shows that there is no unity power factor. 
International Journal on Cybernetics \& Informatics (IJCI) Vol. 5, No. 1, February 2016

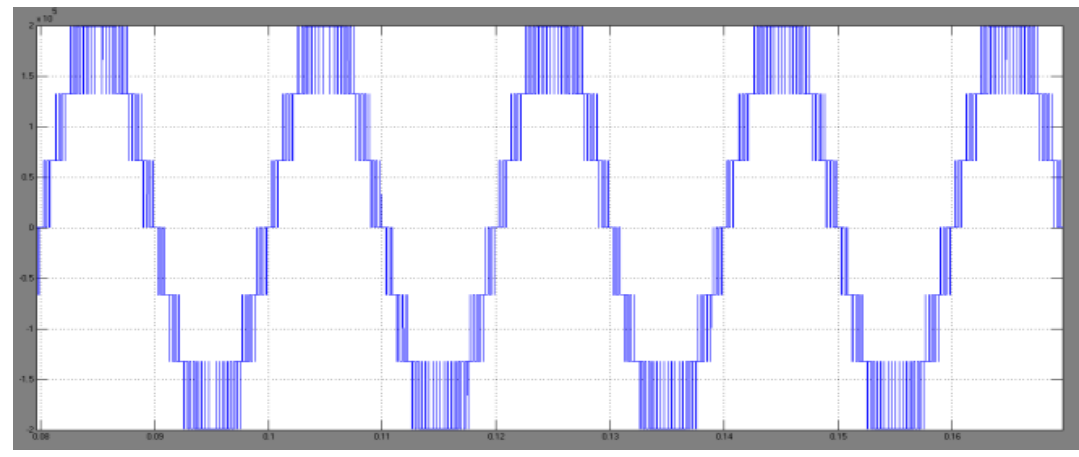

Fig.9.Seven Level output voltage

Figure.9.Shows the Seven level output voltage, when system is connected to cascade seven level multilevel D-STATCOM.
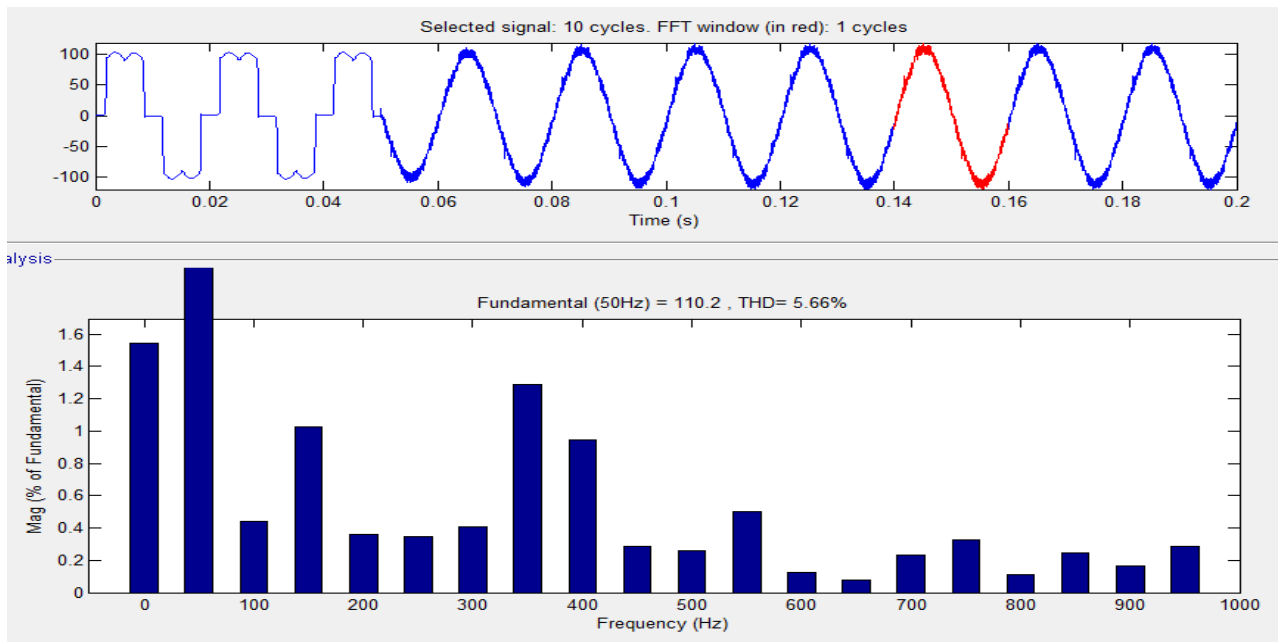

Figure 10: Harmonic spectrum of Phase-A Source current for seven level D-STATCOM

Figure10 shows the harmonic spectrum of Phase -A Source current for balanced non-linear load with cascaded Multilevel Seven level D-STATCOM. The THD of source current is $5.66 \%$.
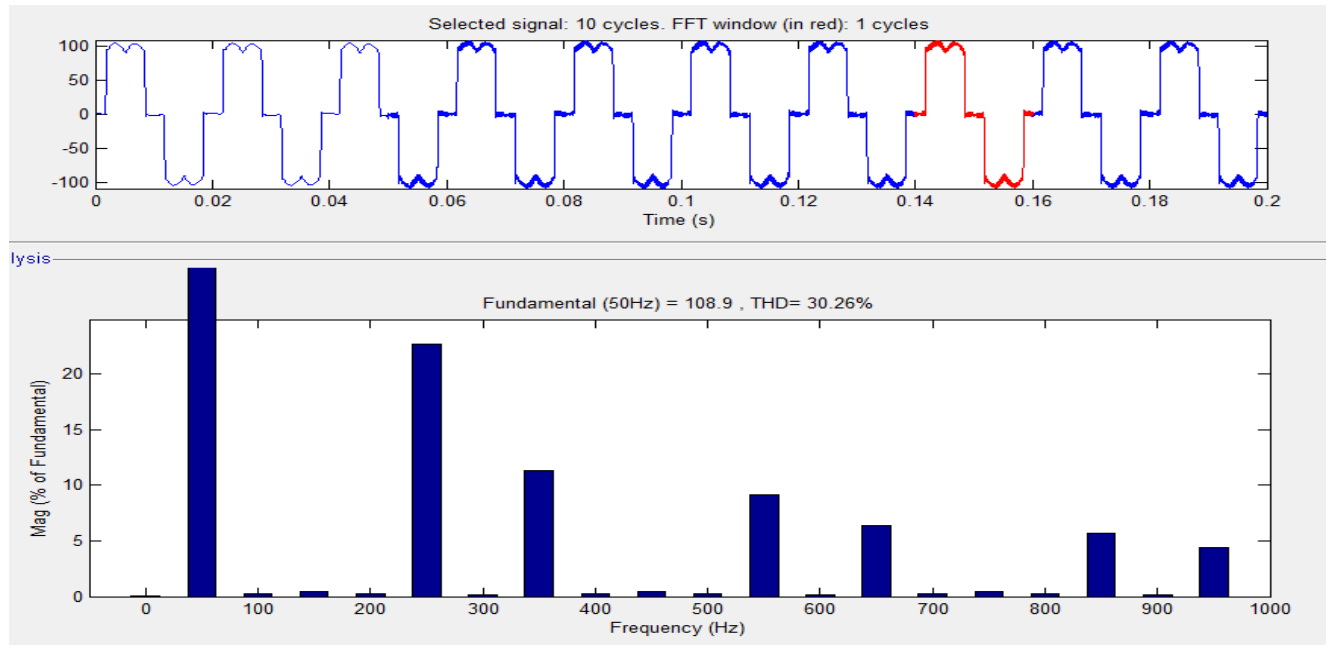

Figure 11: Harmonic spectrum of Phase-A load current for seven level D-STATCOM 
International Journal on Cybernetics \& Informatics (IJCI) Vol. 5, No. 1, February 2016

Figure11 shows the harmonic spectrum of Phase -A Load current for balanced non-linear load with cascaded Multilevel Seven level D-STATCOM. The THD of source current is $30.26 \%$.

\section{Case2. Un-balanced Non-linear load with seven level Cascaded multilevel D-STATCOM.}

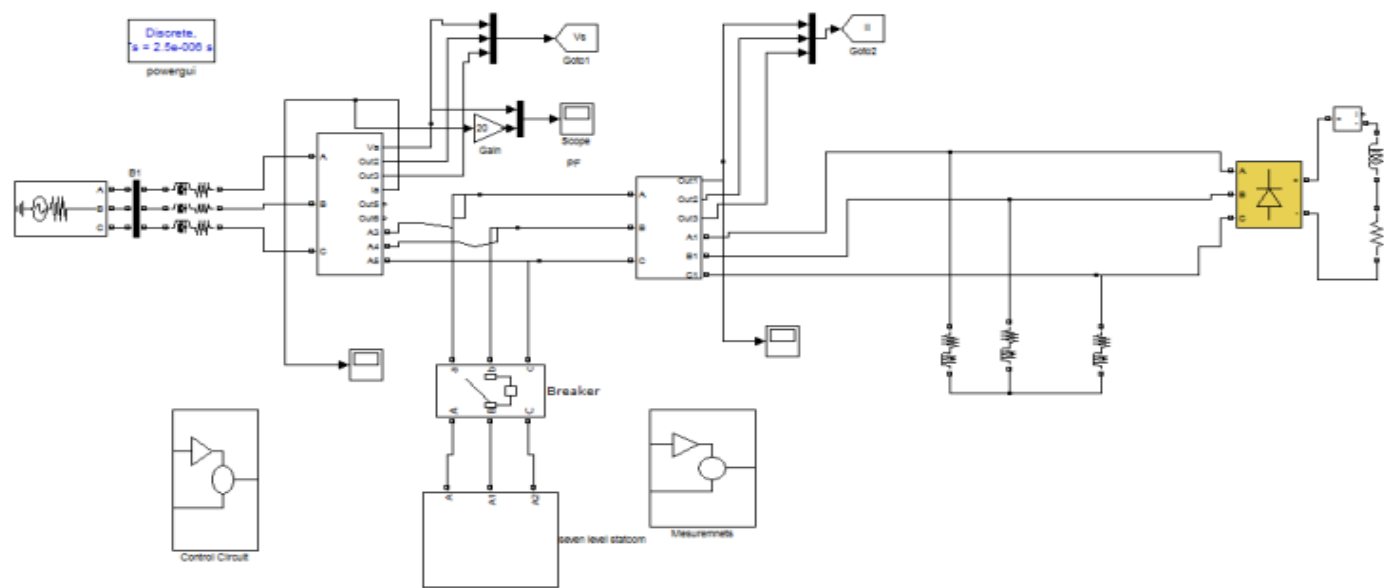

Figure.12.Matlab/Simulink model of unbalanced non-linear load with seven level cascaded multilevel DSTATCOM

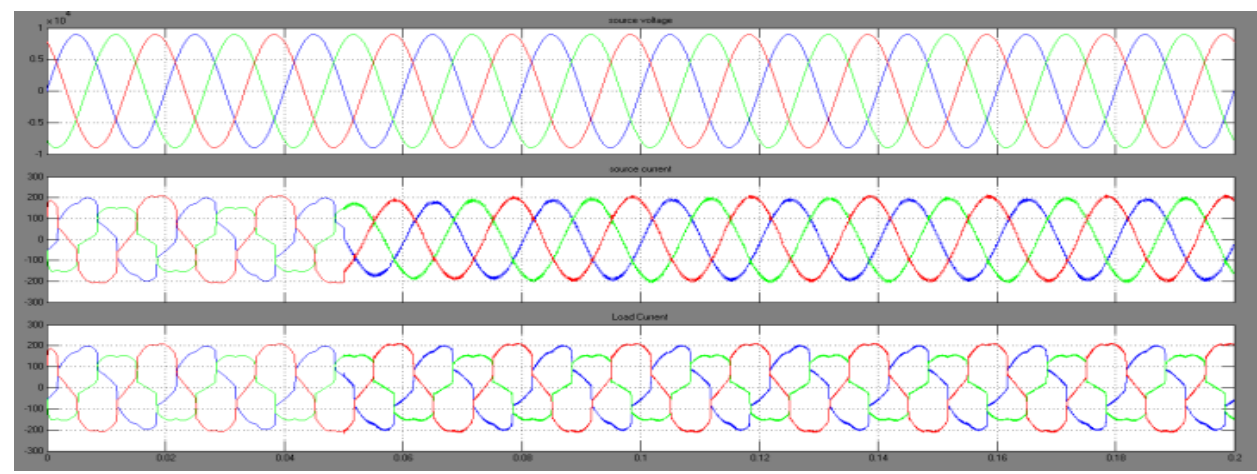

Figure 13: Source voltage, Source current, Load current

Figure-13 shows the source voltages, source currents and load currents for unbalanced non-linear load with Cascaded Multilevel Seven level.

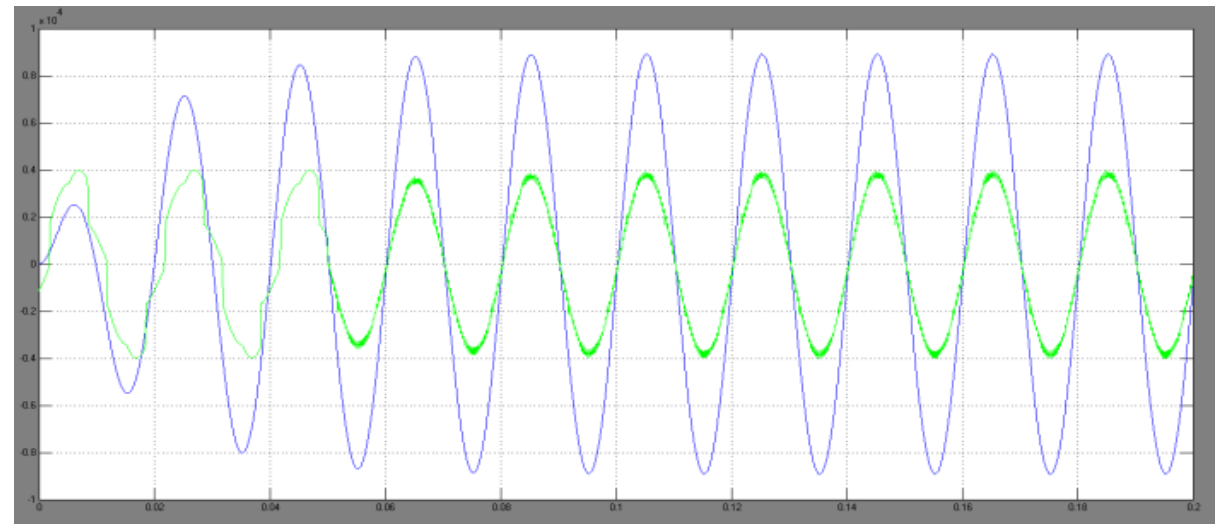

Figure 14: Power Factor with unbalanced non-linear load 
Figure 14 shows the power factor waveforms of the designed system with unbalanced non-liner load seven level cascaded multilevel D-STATCOM.
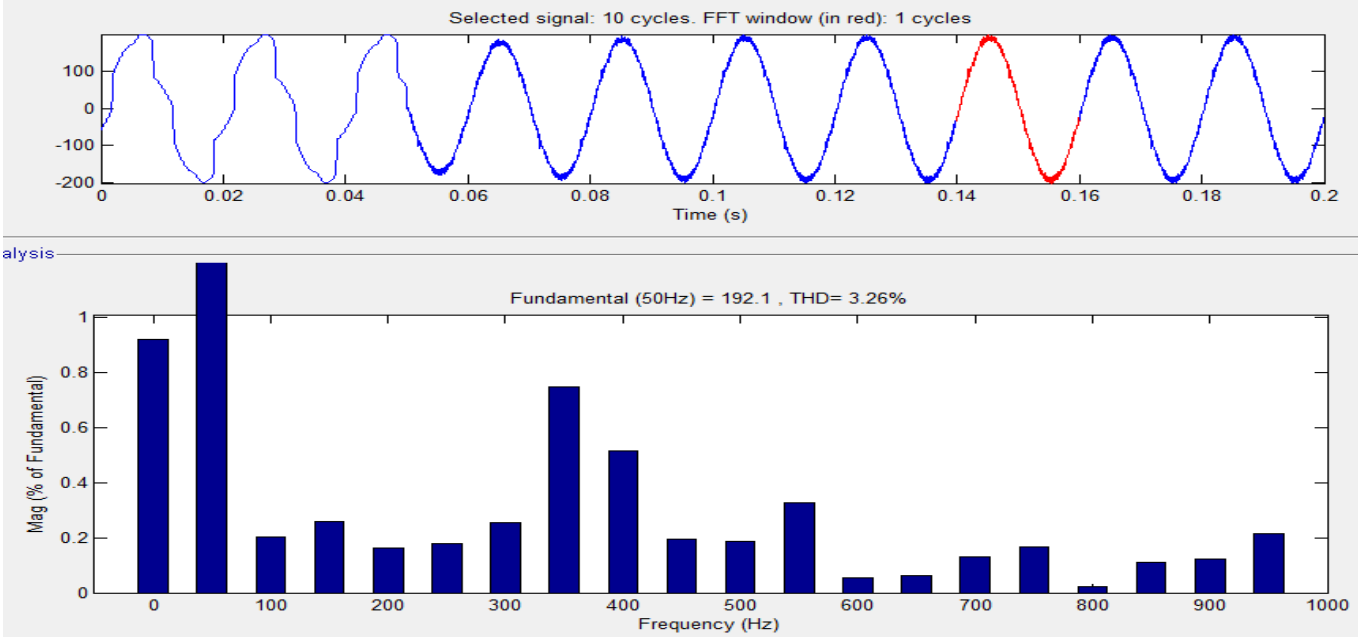

Figure 15: Harmonic spectrum of Phase-A Source current for seven level D-STATCOM

Figure15 shows the harmonic spectrum of Phase -A Source current for unbalanced non- linear load with cascaded Multilevel Seven level D-STATCOM. The THD of source current is $3.26 \%$.
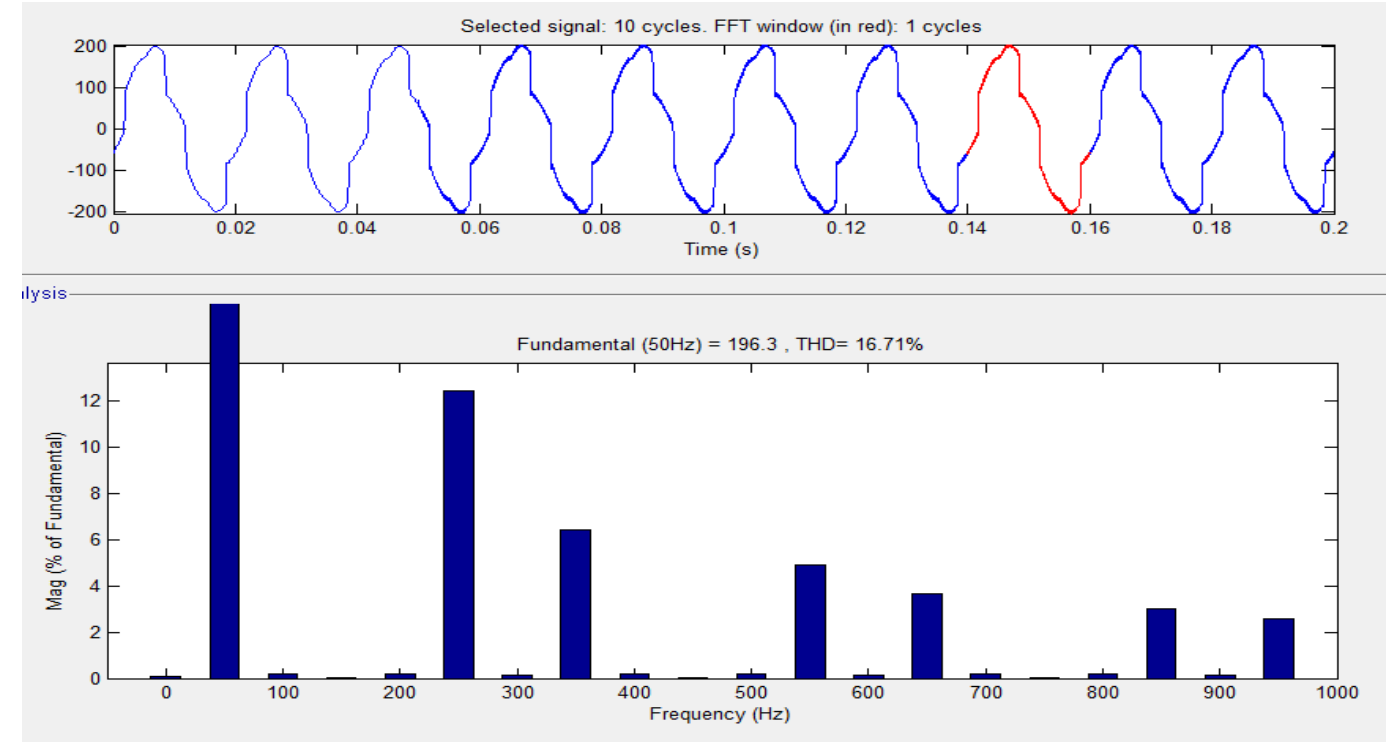

Figure 16: Harmonic spectrum of Phase-A Load current for seven level D-STATCOM

Figure16 shows the harmonic spectrum of Phase -A Load current for unbalanced non- linear load with cascaded Multilevel Seven level D-STATCOM. The THD of load current is $16.71 \%$.

\section{CONCLUSION}

Seven level cascaded multilevel voltage source inverter based D-STATCOM using instantaneous real-power controller is found to be an effective solution for power line conditioning. DSTATCOM with the proposed controller reduces harmonics and provides reactive power compensation due to balanced non-linear and unbalanced non-linear load currents; as a result 
source current(s) become sinusoidal and unity power factor is also achieved under both transient and steady state conditions. The proposed instantaneous real-power controller uses reduced computation for reference current calculations compared to conventional approach. The cascaded inverter switching signals are generated using triangular-sampling current controller; it provides a dynamic performance under transient and steady state conditions.

\section{REFERENCES}

[1] Ghosh and G. Ledwich, Power Quality Enhancement using Custom Power Devices, Kluwer Academic Publisher, Boston, MA, 2002.

[2] Ghosh and G. Ledwich, "Load Compensating DSTATCOM in weak AC systems," IEEE Trans. Power Delivery, vol.18, No. 4, pp. 1302-1309, Oct. 2003.

[3] J. S Lai and F. Z. Peng, "Multilevel converters A new breed of power converters," IEEE Trans. Industry Applications, vol.32, no.3,

[4] F. Z. Peng., J. W. McKeever and, D .J. Adams, "A power line conditioner using cascade multilevel inverters for distribution system," IEEE Trans. Industry Applications, vol.34, no.6, pp. 1293-1298, Nov.-Dec.1998.

[5] W. Liqiao, L. Ping, L. Jianlin and Z. Zhongchao, "Study on shunt active power filter based on cascaded multilevel converters," 35th IEEE Power Electr. Spec. Conf. (APEC), vol.5, pp. 3512-3516, 20-25 June 2004.

[6] H. Gruning,"Power Electronics Circuit Arrangement having Plural Power Converters", U.S. Patent No. 5,805,487, 1998 .

[7] G. Carrara, S. Gardelta, M. Marchesoni,"A new multilevel PWM method: theoretical analysis”, IEEE Trans. On power electronics Vol. 7. No. 3 , July, pp.497-505, 1992.

[8] V. Agelidis, M. Calais," Application specific harmonic performance evaluation of multicarrier PWM techniques”, IEEE-PESC'98 Conference Record, pp. 172-178, 1998. 